\title{
The importance of good dialogue between healthcare professionals and people with obesity
}

1. Angela Golden NP from Home, LLC. Munds Park, AZ, USA

2. Joseph Nadglowski Obesity Action Coalition, Tampa, FL, USA

3. Kenneth J. Tomaszewski KJT Group, Inc.

Honeoye Falls, NY, USA
4. Madhuri Mehta Novo Nordisk Inc.

Plainsboro, NJ, USA

5. Boris Stevenin Novo Nordisk Inc., Plainsboro, NJ, USA

6. Michelle Look San Diego Sports Medicine and Family Health, San Diego, CA, USA

\section{Background}

- Despite the growing recognition of obesity as a disease many people with obesity (PwO) remain untreated by healthcare professionals (HCPs). Understanding the challenges in managing obesity can guide improvements in the communication between PwO and HCPs, increasing the chances of successful weight loss.

- The ACTION (Awareness, Care, and Treatment In Obesity maNagement) study examined perceptions, attitudes, and behaviours related to obesity management among PwO and HCPs.

\section{Objectives}

- Gain a better understanding of the barriers that can prevent PwO from receiving high quality care and support to manage their obesity.

- Generate insights to help guide collaborative action to promote effective care for PwO.

- Compare perceptions, attitudes, and behaviours between PwO and HCPs.

\section{Study design}

- This study consisted of a cross-sectional, US-based, stratified sampling of people with obesity (PwO) and health care professionals (HCPs) involved in weight management.

- All PwOs had BMI $\geq 30 \mathrm{~kg} / \mathrm{m}^{2}$ based on self-reported height and weight. HCPs included primary care physicians (PCPs) and obesity specialists (those identifying as an obesity specialist and/or seeing at least $50 \%$ of patients for obesity).

- The 40-45-minute survey assessed attitudes, experiences and behaviours associated with medical-based obesity management.

- Respondents were recruited though an online panel. Study and survey instruments used were Institutional Review Board approved.

\section{Statistical analysis}

- Respondent-level weighting was applied to the PwO sample to test demographic targets for age, household income, ethnicity, race and Hispanic descent, gender, and US Region based on the 2010 US Census. Sample sizes presented are unweighted.

- Descriptive statistics (\%, other) are weighted figures, unless otherwise noted.

- Statistical significance was set at $p<0.05$, using 2-tailed tests.

\section{Sample characteristics}

- Table 1 shows the characteristics of the 3008 PwO and 606 HCP who completed the survey and were included in the analysis.

\section{PwO sub-group definitions}

- Successful weight loss (WL): lost 10\% body weight and kept it off for at least 1 year.

- Actively seeking treatment: committed to a weight loss plan, successfully lost weight and kept it off, or has spoken to HCP about weight loss in past 6 months.

\section{Results}

Weight loss responsibility and obesity diagnosis

- $82 \%$ PwO agreed that WL was 'completely' their responsibility while $72 \%$ HCPs agreed that HCPs were responsible for 'contributing' to PWO WL efforts.

- 55\% of PwO reported receiving a formal obesity diagnosis however, PwO who were actively seeking treatment $(n=1455)$ or who had successful WL $(n=261)$ were more likely to report having an obesity diagnosis (57\% vs. $51 \%$ and $69 \%$ vs. $53 \%$ respectively; $p<0.05$ ).

\section{Appointments for weight management}

- $71 \%(n=2,185)$ of PwO had spoken with an HCP about their weight within the past 5 years. Of these, $24 \%$ reported having scheduled follow-up appointments, 67\% of whom intended to keep them.

\begin{tabular}{llcc}
$\begin{array}{l}\text { Table } \mathbf{1} \text { Characteristics of PwO and HCP. } \\
\text { Characteristics (unweighted) }\end{array}$ & $\begin{array}{c}\text { PwO Total } \\
\text { (n=3008) }\end{array}$ & $\begin{array}{c}\text { HCP Total } \\
\text { (n=606) }\end{array}$ \\
\cline { 2 - 4 } & Male & $1378(46)$ & $305(50)$ \\
Sex, N (\%) & Female & $1630(54)$ & $301(50)$ \\
\hline Age [SD] & Mean & $54[14]$ & Category ranges asked \\
\hline BMI [SD], kg/m² & Body mass index, mean & $37[6]$ & $25[5]$ \\
& Family practice & & $298[49]$ \\
& General practice & $49[8]$ \\
\hline Provider Specialty, N (\%) & Internal medicine & & $241(40)$ \\
\hline
\end{tabular}

Figure 1 Feelings after most recent discussion of weight with HCP.

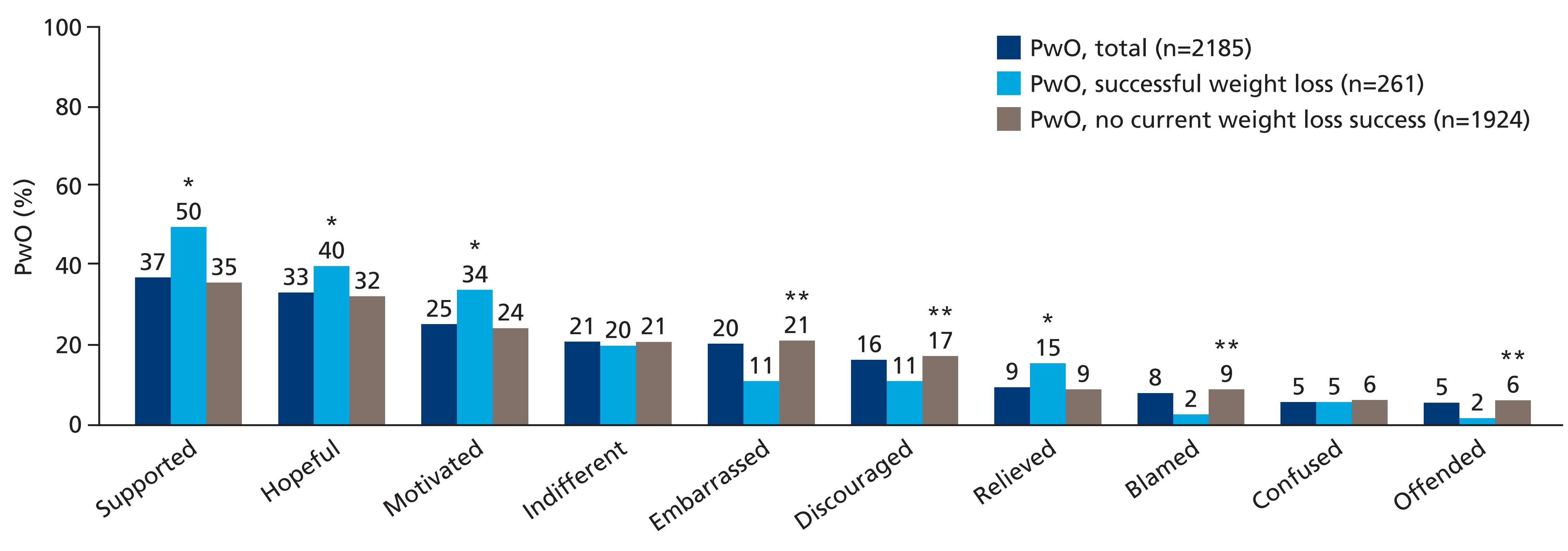

Table 2 Treatments discussed with HCP.

\section{Weight Loss Strategies}

PwO discussing treatment (\%)

General improvement in eating habits/reducing calories

Specific diet or diet programme

Generally be more active/increase in physical activity

A formal exercise programme/gym membership/personal trainer

Meal/nutrient tracking (on paper or an app)

Exercise tracking (on paper or an app)

Visiting a nutritionist/dietician

Prescription weight loss medication

Visiting a weight loss specialist or a weight loss clinic

Weight loss surgery

Therapy such as counselling or lifestyle modification

Over-the-counter weight loss medication

- When asked why they did not initiate discussions about WL with their patients, 52\% of HCPs cited a lack of time during the appointment. $45 \%$ thought there were more important issues to discuss, $27 \%$ believed the patient was not motivated to lose weight, $26 \%$ that the patient was not interested in losing weight and $22 \%$ had concerns about the patient's emotional state or psychological issues.

Attitudes towards weight management discussions

- The majority of PwO felt comfortable talking to their HCP about their weight and trusted their advice.

- Only $17 \%$ of PwO felt their HCPs did not listen to what they said about their weight and 19\% thought that the HCP did not understand the difficulties of weight management.

- PwO with successful WL were significantly more likely to have positive feelings about WL discussions $(p<0.05)$ (Figure 1).

\section{Obesity treatment discussions}

- Despite recent treatment developments in WL, clinica discussions focused more on healthy eating and physica activity rather than behavioural modifications or medical options (Table 2).

\section{Discussion}

- PwO perceive WL is completely their responsibility and often do not recognise their disease.

- HCPs believe that they are responsible for helping their patients lose weight, however de-prioritise weight issues in the limited consultation time available.

- Many PwOs feel supported, hopeful and motivated after WL discussions, particularly those with WL success.

- Being formally diagnosed with obesity is an important driver in WL success, as is actively seeking treatment.

\section{Conclusions}

- Simple solutions to aid with HCPs management of PwOs: initiating discussions about weight, recognising patients' WL attempts, scheduling follow up appointments, and formally diagnosing obesity.

- HCPs may also consider individualising treatment discussions beyond diet and exercise based on their weight discussions with PwOs. 